\title{
Study on Carbide Tool Performance in Green Machining of Aeronautical Material: Q-T Models and Finite Element Analysis
}

\author{
Armansyah Ginting ${ }^{1}$
}

\begin{abstract}
Through the experimental work on dry end milling of an aeronautical material Ti-6242S, the extended Taylor models for volume of material removal $\left(Q . V_{c}^{2.2-}\right.$ $\left.f_{z}^{1.98} \cdot a_{a}^{1.96}=3.318 \times 10^{3}\right)$ and tool life $\left(T . V_{c}^{3.3} \cdot f_{z}^{2.97} \cdot a_{a}^{2.80-}\right.$ $=1.531 \times 10^{6}$ ) are resulted for characterizing the performance of the off-centre ball end milling alloyed carbide tool $(\mathrm{W}-(\mathrm{Ti} / \mathrm{Ta} / \mathrm{Nb}) \mathrm{C}-\mathrm{Co})$. Further analysis on the models result the optimum cutting conditions $\left(V_{c} 88 \mathrm{~m} / \mathrm{min}\right.$ at $f_{z}$ $0.20 \mathrm{~mm} /$ tooth, $V_{c} 113.5 \mathrm{~m} / \mathrm{min}$ at $f_{z} 0.15 \mathrm{~mm} /$ tooth, and $V_{c}$ $163 \mathrm{~m} / \mathrm{min}$ at $f_{z} 0.10 \mathrm{~mm} /$ tooth) as the best compromise among cutting speed $\left(V_{c}\right)$, material removal rate $(\mathrm{MRR}=\mathrm{Q} / \mathrm{T})\left(\mathrm{cm}^{3} / \mathrm{min}\right)$ and $\mathbf{T}(\mathrm{min})$. Moreover, it can be interpreted that the tool failure mode, tool wear mechanism and the behaviour of tool performance are changing at the optimum cutting conditions given by the models that plot in a chart of MRR-T- $V_{c}$. By utilizing the FEM simulation, the chip morphology, contact length at the tool-chip interface and the tribological aspects (temperature, pressure) in machining at the optimum cutting conditions can be evaluated. The results of simulation support the interpretation of experimental results.
\end{abstract}

Keywords - Extended Taylor model, Chip morphology, material removal rate, Optimum cutting condition, Tribological aspects.

\section{PENDAHULUAN}

$\mathrm{T}$ he problem addressed by the study reported in this paper is the issue on dry machining. Dry machining has two main impacts on metal cutting industry, i.e. ecology and economy. For the ecology aspect, as far as cutting fluids are concerned, changes in ecological legislation -mainly in European countries- imposed increasing pressure upon the metal cutting industry. For the economy, cutting fluids represent $16-20 \%$ of the production cost [1].

There are two main purposes of cutting fluids used in metal cutting process, i.e. as a lubricant and as a coolant. The absence of cutting fluids in metal cutting means higher friction and higher cutting temperature during cutting. They become serious problems for machinability (tool life and surface finish) because at the same time; the machining parameters should keep equal to the condition of machining under wet cutting (even for high speed machining). Since cutting fluid is absent in dry machining, the only one opportunity to ensure dry

Manuscript received July 6, 2007; revised May 21, 2008

${ }^{1}$ Armansyah G. is with department of Mechanical Engineering, Faculty of Engineering, University of Sumatera Utara, INDONESIA machining can successfully be done in metal cutting is to provide a suitable cutting tool.

The objective of the present study, in general, is seeking the suitable cutting tool for dry machining of aerospace material (titanium based alloy) and particularly in this paper; performance of the alloyed carbide tool is studied. The expected goals from this study are the tool life model and the optimum cutting condition of the alloyed carbide tool when used in end milling of titanium alloy Ti-6242S under dry cutting environment.

\section{MATERIALS AND METHODS}

\section{A. Materials}

The forging stock of the $(\alpha+\beta)$ titanium alloy Ti$6242 \mathrm{~S}$ is the workpiece material in this study. The chemical composition and physical properties of this material are given in Tables 1 and 2, respectively. In order to minimize the effect of previous processes in material production, prior to the end milling trials, the workpiece materials were trued and cleaned by face milling their outer surfaces.

The cutting experiments were carried out using the alloyed carbide tool insert (grade P of ISO codes) with insert diameter $\left(D_{i}\right)$ of $12 \mathrm{~mm}$ (see Table 3). In end milling trials, each insert was rigidly mounted on a tool holder to provide the off centre ball end mill configuration with nominal diameter $\left(D_{n}\right)$ of $16 \mathrm{~mm}$ and the tool geometry of cutting rake $(\gamma o)-6^{\circ}$, axial rake $(\gamma p)-6^{\circ}$, and radial rake $(\gamma f)-2^{\circ}$ (Figure 1 ). The ball end mill tool configuration and end milling process are selected since they are widely used in machining the complex profiles (contouring) of aerospace components such as turbine blade in which Ti-6242S is used to replace the Ti-64 [2].

\section{B. Methods}

Machining trials were carried out on a 3-axis CNC vertical milling machine with $9 \mathrm{~kW}$ motor. This machine has a variable spindle speed range from 60 to 10,000 rpm.

The tool rejection criteria stipulated for the end milling trials were based on the ISO 8688-2 [3] where uniform flank wear (VB1) $\geq 0.2 \mathrm{~mm}$, non-uniform flank wear $(\mathrm{VB} 2) \geq 0.8 \mathrm{~mm}$, localized flank wear $(\mathrm{VB} 3) \geq 0.9$ $\mathrm{mm}$, machining time maximum $\geq 20$ minutes and minimum $\geq 3$ minutes. The cutting conditions for testing are arranged as follows: 

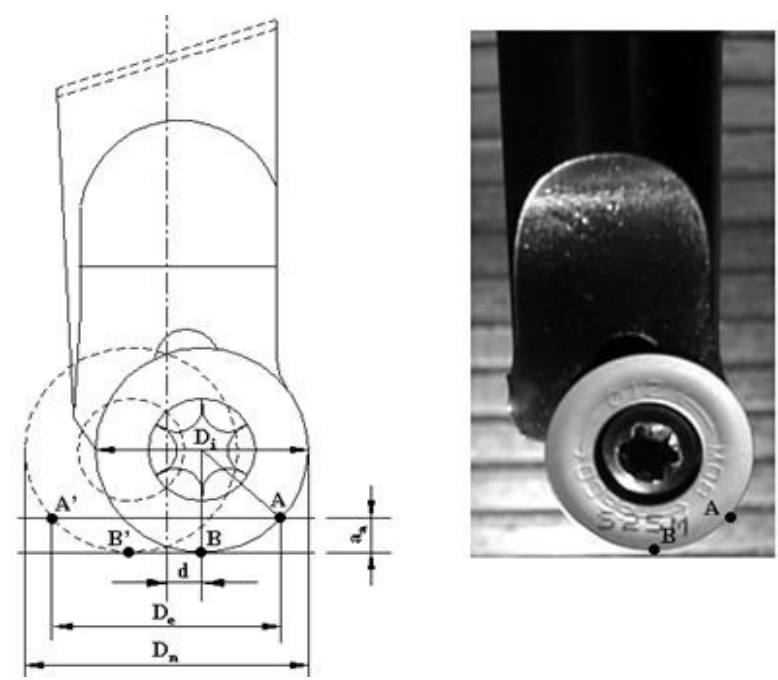

radius).

TABLE 1

CHEMICAL COMPOSITION OF TI-6242S

\begin{tabular}{|c|c|c|}
\hline Elements & Min.(\%) & Max.(\%) \\
\hline $\mathrm{Al}$ & 5.50 & 6.50 \\
\hline $\mathrm{Zr}$ & 3.60 & 4.40 \\
\hline $\mathrm{Mo}$ & 1.80 & 2.20 \\
\hline $\mathrm{Sn}$ & 1.80 & 2.20 \\
\hline $\mathrm{Fe}$ & - & 0.25 \\
\hline $\mathrm{O}_{2}$ & - & 0.15 \\
\hline $\mathrm{Si}$ & - & 0.10 \\
\hline $\mathrm{C}$ & - & 0.05 \\
\hline $\mathrm{N}_{2}$ & - & 0.05 \\
\hline $\mathrm{H}_{2}$ & - & 0.015 \\
\hline $\mathrm{Y}$ & - & 0.005 \\
\hline $\mathrm{Others}$ & 0.100 & 0.300 \\
\hline $\mathrm{Ti}$ & to $100 \%$ & \\
\hline \multicolumn{2}{|l}{} \\
\hline
\end{tabular}

TABLE 2

PHYSICAL PROPERTIES OF TI-6242S

\begin{tabular}{|l|l|}
\hline Tensile strength $(\mathrm{MPa})$ & $\geq 895$ \\
\hline Yield strength $(\mathrm{MPa})$ & 830 \\
\hline Creep stress $(\mathrm{MPa})$ & 240 \\
\hline Hardness $(\mathrm{HRc})$ & $\sim 36$ \\
\hline Density $\left(\mathrm{kg} / \mathrm{m}^{3}\right)$ & 4540 \\
\hline Linear thermal expansion $\left(10^{-6} /{ }^{\circ} \mathrm{C}\right)$ & 9.9 \\
\hline Thermal conductivity $(\mathrm{W} / \mathrm{mK})$ & $8-12$ \\
\hline
\end{tabular}

TABLE 3

THE PROPERTY OF CUTTING TOOL

\begin{tabular}{|l|c|}
\hline \multicolumn{1}{|c|}{ Composition } & $\begin{array}{c}\mathbf{6 9 . 8 \%} \mathbf{W C} \\
\mathbf{9 . 5 0 \%} \mathbf{C o} \\
\mathbf{2 0 . 7 \%}(\mathbf{T i} / \mathbf{T a} / \mathbf{N b})\end{array}$ \\
\hline Grain size $(\mu \mathrm{m})$ & $1-2$ \\
\hline Hardness $25^{\circ} \mathrm{C}\left(\mathrm{HV}_{10}\right)$ & 1485 \\
\hline Hot hardness $800^{\circ} \mathrm{C}\left(\mathrm{kg} / \mathrm{mm}^{2}\right)$ & 600 \\
\hline Density $\left(\mathrm{g} / \mathrm{cm}^{3}\right)$ & 11.4 \\
\hline Thermal conductivity $(\mathrm{W} / \mathrm{mK})$ & 45 \\
\hline Thermal expansion $\left(10^{-6} / \mathrm{K}\right)$ & 6.1 \\
\hline Modulus of elasticity $(\mathrm{GPa})$ & 510 \\
\hline Traverse rupture $(\mathrm{GPa})$ & 2.2 \\
\hline
\end{tabular}

1. Sensitivity stage. In this stage, the cutting condition is based on the suggestion of the tool manufacturer. Cutting condition was started from $60 \mathrm{~m} / \mathrm{min}$ and the cutting speed was step by step increased up to tool life about 5 minutes. The 5 minutes tool life is considered as the minimum limit to determine the highest cutting speed in cutting tool testing [3]. The output of this stage is the cutting condition with tool life criteria of ( 5 minutes $<$ tool life $<20$ minutes).

2. Performance stage. The cutting condition resulted from the previous stage was intensively tested in this stage. In the meaning of obtaining the reliable results and resulting the extended Taylor tool life model (T), the factorial design $2^{3}$ with 4 centre points and 3 replications (total 36 data) was utilized. Besides tool life model, the model for volume of material removal (Q) was also the output of this stage.

The extended Taylor tool life model resulted from the performance stage was used to simulate the various cutting conditions. From the simulation, tool life (T) and Material Removal Rate (MRR) that obtained from $(\mathrm{Q} / \mathrm{T})$ were plotted to determine the optimum cutting condition of the alloyed carbide tool. Finally, in order to support the results of experimental works, the machining simulation by Thirdwave Advantedge software was carried out.

\section{RESULT AND DISCUSSION}

\section{A. Sensitivity stage}

The cutting conditions used in this stage was started from cutting speed $\left(V_{c}\right)$ of $60 \mathrm{~m} / \mathrm{min}$, tooth feed $\left(f_{z}\right)$ of $0.1 \mathrm{~mm} /$ tooth, axial depth of cut $\left(a_{a}\right)$ of $2 \mathrm{~mm}$ and radial depth of cut $\left(a_{r}\right)$ of $8.8 \mathrm{~mm}$ (or $55 \%$ of tool nominal diameter) ( $a_{a}$ and $a_{r}$ were kept constant for the experimental work). This combination is a typical cutting condition used for roughing operation in the manufacturing industry and as the suggestion of tool's manufacturer.

The results of end milling testing at this stage are presented in Figures 2 and 3. It can be seen that at constant axial and radial depth of cuts, cutting condition for the alloyed carbide tool can be increased up to cutting speed of $150 \mathrm{~m} / \mathrm{min}$ and tooth feed of $0.15 \mathrm{~mm} /$ tooth (higher cutting speed of $175 \mathrm{~m} / \mathrm{min}$, tool life is less than 5 minutes and may end with catastrophic failure). At all cutting conditions (from 60 to $150 \mathrm{~m} / \mathrm{min}$ ), it was observed that localized flank wear (VB3) could be the main criterion to determine tool life.

Based on tool life and flank wear progression data plotted in Figures 2 and 3 and supported by the analysis of surface topography of the machined surface (the detail analysis of surface topography is not reported in this paper); the cutting conditions recommended for the performance stage are cutting speeds of $100-125 \mathrm{~m} / \mathrm{min}$, feeds of $0.15-0.20 \mathrm{~mm} /$ tooth, axial depth of cut of 2-2.5 $\mathrm{mm}$ and radial of $8.8 \mathrm{~mm}$ or $55 \%$ of tool's nominal diameter. These cutting conditions were considered as the low and high limits in where the optimum cutting conditions could be obtained.

\section{B. Performance stage}

The trials at this stage prove that localized flank wear (VB3) is the main criterion to determine tool life of the alloyed carbide tool when used to end milling of titanium alloy Ti-6242S under dry machining environment (see Figure 4). The localized flank wear was found located at 
the tool leading edge area or shown by point $\mathrm{A}$ at Figure 1. The localization at the leading cutting edge is due to the fact that this area is the frontier of contact (interrupted cutting) between tool and workpiece and all cutting loads (mechanical and thermal) are concentrated at this area.

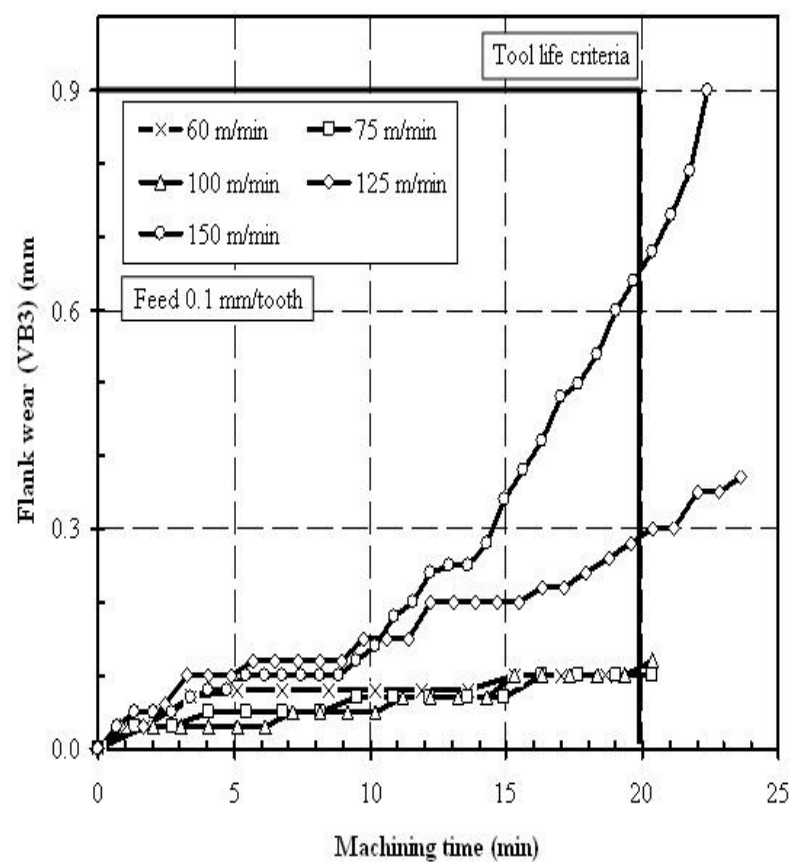

Fig. 2. Flank wear progression at tooth feed of $0.1 \mathrm{~mm} /$ tooth.

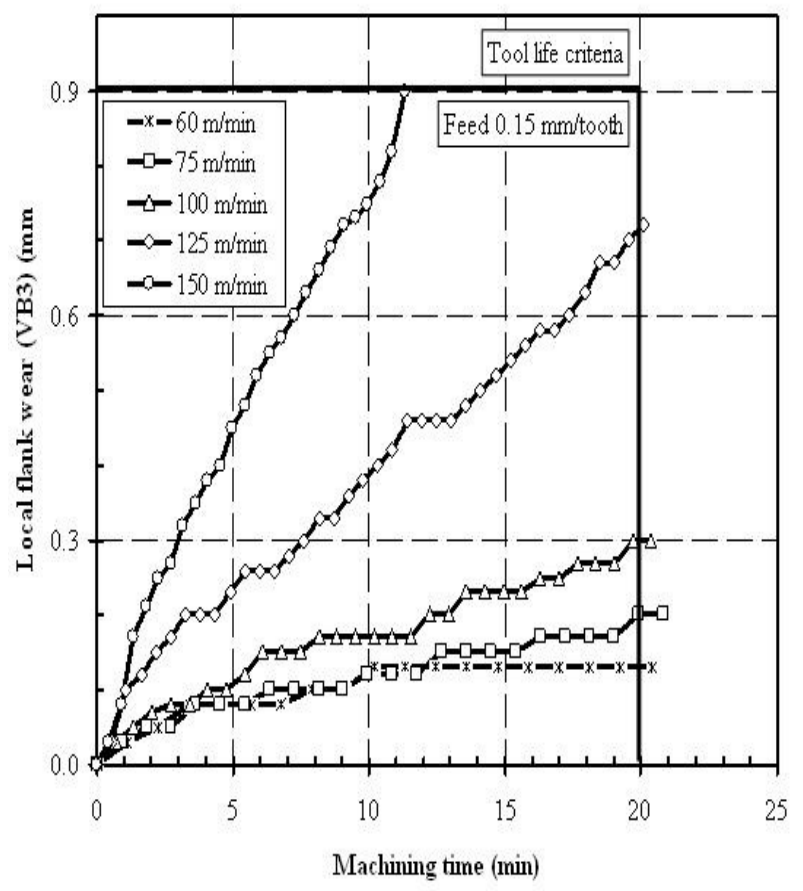

Fig. 3. Flank wear progression at tooth feed of $0.15 \mathrm{~mm} /$ tooth.

The results of testing for cutting conditions as recommended by the sensitivity stage are presented in Figures 4 and 6. In Figure 4, tool life (min) is plotted against cutting speed $(\mathrm{m} / \mathrm{min})$, and in Figure 6 , tool life $(\mathrm{min})$ is plotted against volume of material removed $\left(\mathrm{cm}^{3}\right)$. From all data plotted in both figures and by utilizing the multiple regression method [4], the extended Taylor tool life model $(\mathrm{T})$ and the volume of material removed $(\mathrm{Q})$ model are resulted:

$T V_{c}^{3.3} f_{z}{ }^{2.97} a_{a}{ }^{2.8}=1.767 \times 10^{6}$

$Q V_{c}{ }^{2.2} f_{z}{ }^{1.98} a_{a}{ }^{1.96}=3.318 \times 10^{3}$

From the data plotted in Figure 5, it is recorded that tool life of cutting speeds between $100-115 \mathrm{~m} / \mathrm{min}$ is ranging from 5 to 15 minutes. This value is higher enough to claim that the alloyed carbide tool used in this study is potential to be used for dry end milling of Ti$6242 \mathrm{~S}$. This fact is contrary to the results of some previous researchers [5-7] that reported the alloyed carbide tool is not recommended for machining of titanium alloy due to high crater and flank wear rate.

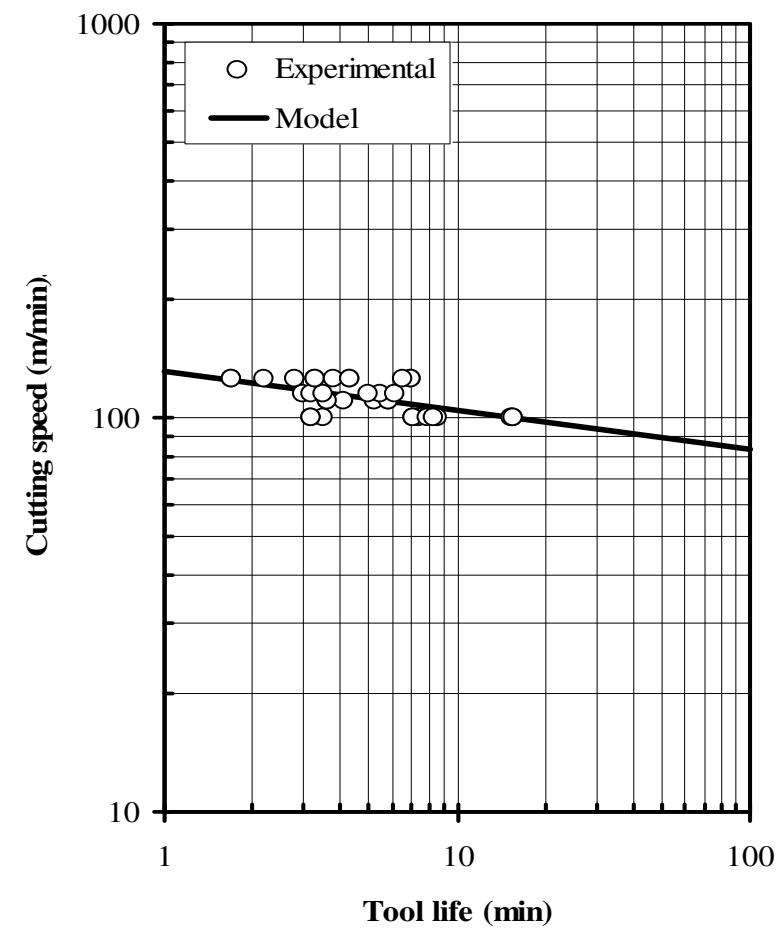

Figure 4. Tool life (min) vs. cutting speed (m/min).

\section{Optimum cutting conditions}

Once the models are obtained for T and Q, the models can be used to simulate the behaviour various values of cutting conditions. Since we have T $(\mathrm{min})$ and $\mathrm{Q}\left(\mathrm{cm}^{3}\right)$, thus the material removal rate (MRR) can be calculated by $(\mathrm{Q} / \mathrm{T})\left(\mathrm{cm}^{3} / \mathrm{min}\right)$.

In Figure 7, the T model is used to simulate the results of tool life (TLm) for various cutting speeds and tooth feeds of $0.1,0.15$ and $0.2 \mathrm{~mm} /$ tooth. In the similar meaning, the $\mathrm{Q}$ model is also used to simulate the metal removal rate (MRRm).

From Figure 7, it can be seen that tool life (TLm) is decreasing as the increasing of cutting speed, while the material removal rate (MRRm) shows a contrast behaviour. The behaviour of tool life curve can be divided into three stages:

1. The linear stage. It is occurred from cutting speed of 60 to $75 \mathrm{~m} / \mathrm{min}$ (for tooth feed of $0.2 \mathrm{~mm} /$ tooth), 100 $\mathrm{m} / \mathrm{min}(0.15 \mathrm{~mm} /$ tooth $)$, and $125 \mathrm{~m} / \mathrm{min} \quad(0.1$ $\mathrm{mm} /$ tooth). At this stage, tool life is dramatically 


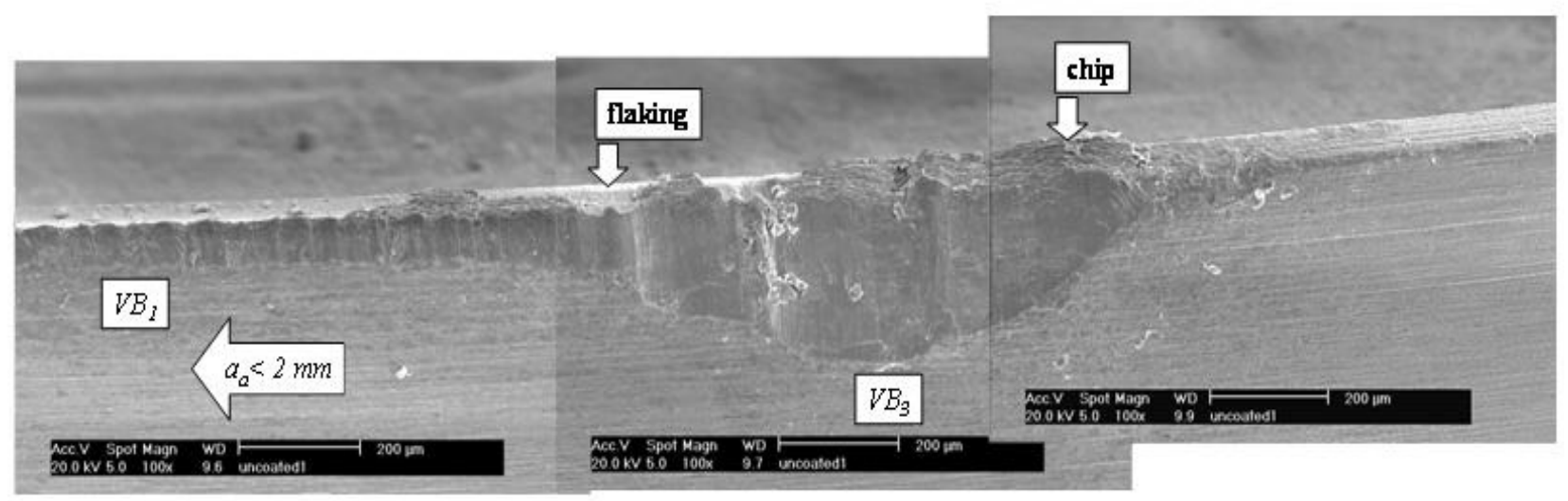

Fig. 5. Localized flank wear (VB3) at the tool leading edge area.

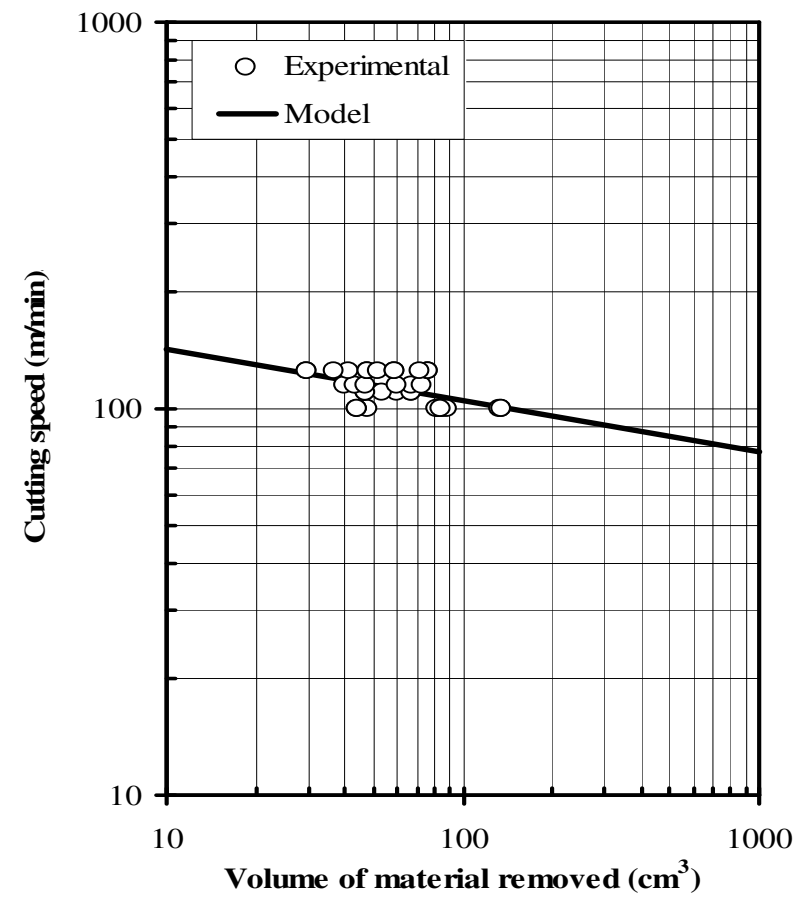

Fig. 6. Volume of material removed $\left(\mathrm{cm}^{3}\right) v s$. cutting speed $(\mathrm{m} / \mathrm{min})$.

decreasing as the increasing of cutting speed and no intersection point between tool life curve and material removal rate curve is found.

2. The regular stage. This stage is the continuation of the linear stage and at all values of tooth feed; the stage is ending at cutting speed of $225 \mathrm{~m} / \mathrm{min}$. At this stage tool life is regularly decreasing as the increasing of cutting speed and all tool life curves are intersection with all material removal rate curves. At tooth feed of $0.2 \mathrm{~mm} /$ tooth, the intersection point between tool life curve and material removal rate curve is at cutting speed of $88 \mathrm{~m} / \mathrm{min}$, at tooth feed of $0,15 \mathrm{~mm} /$ tooth is at cutting speed of $113.5 \mathrm{~m} / \mathrm{min}$, and at tooth feed of 0.1 $\mathrm{mm} /$ tooth is at cutting speed of $163 \mathrm{~m} / \mathrm{min}$. Those three points are the points that we consider as the optimum cutting condition for the alloyed carbide tool when used to end milling of titanium alloy Ti-6242S under dry machining environment. It is expected that at those three points the best compromise among cutting speed, tool life and metal removal rate can be achieved and thus, the productivity is optimum. Tooth feeds of $0.1,0.15$ and $0.2 \mathrm{~mm} /$ tooth are selected for simulation based on the results of experimental works on the sensitivity and performance stages.

3. The horizontal stage. This stage is the continuation of the regular stage. It is believed that tool life curve is continuously decreasing even at small gradient and this curve will end at a certain cutting speed in which cutting tool is instantaneously severe damage just after the first contact of interrupted cutting (a premature tool breakage or failure).

\section{Tool wear and wear mechanism}

From the study on wear mode and wear mechanism, it can be observed that wear mode of alloyed carbide tool used for cutting below the optimum cutting condition is more on the uniform flank wear (VB1) and its wear mechanism is the adhesive wear.

In the case of cutting at the above of the optimum cutting condition, wear mode is more on the localized flank wear (VB3) and this mode is followed by plastic deformation and brittle fracture (cracking, flaking and chipping). For the wear mechanism, besides adhesive wear (attrition and galling), dissolution-diffusion is also evidenced.

It is believed that the wear mode and its mechanism when machining below the optimum cutting speed are due to mechanical load phenomenon other than thermal load phenomenon when machining above the optimum cutting condition.

From the description in the above, it can be interpreted that the tool failure mode or wear mode, tool wear mechanism and the behaviour of tool performance (the combination among cutting speed, tool life and metal removal rate) are changing at the optimum cutting conditions given by the model.

\section{E. Machining simulation}

The main purpose of machining simulation carried out in this study is to obtain the cutting temperature of trials at the optimum cutting condition. It is difficult to measure cutting temperature during the tests since tool is moving in thousands rpm and the cutting zone (contact length at the tool-chip interface) when machining of titanium alloy is very narrow. Besides cutting temperature, the machining simulation can also provide some other information such as chip 
morphology, primary shear angle, contact length and cutting pressure.

In Figures 8, the results of machining simulation on chip morphology and the distribution of temperature are presented. From the shape of chips, it can be observed that the serrated chip as the common chip of titanium alloy is successfully obtained. From the figures, it can be seen and obtained that the higher the cutting speed, the curly the chip curvature, the lower the shear angle and the shorter is the contact length. In the case of temperature, it is obtained that the higher the cutting speed, the higher is the cutting temperature. In Figure 9, the cutting temperature among three points of the optimum cutting conditions is compared. Those values show that the cutting temperature is the ideal temperature to ensure the occurrence of dissolution-diffusion wear mechanism [7].

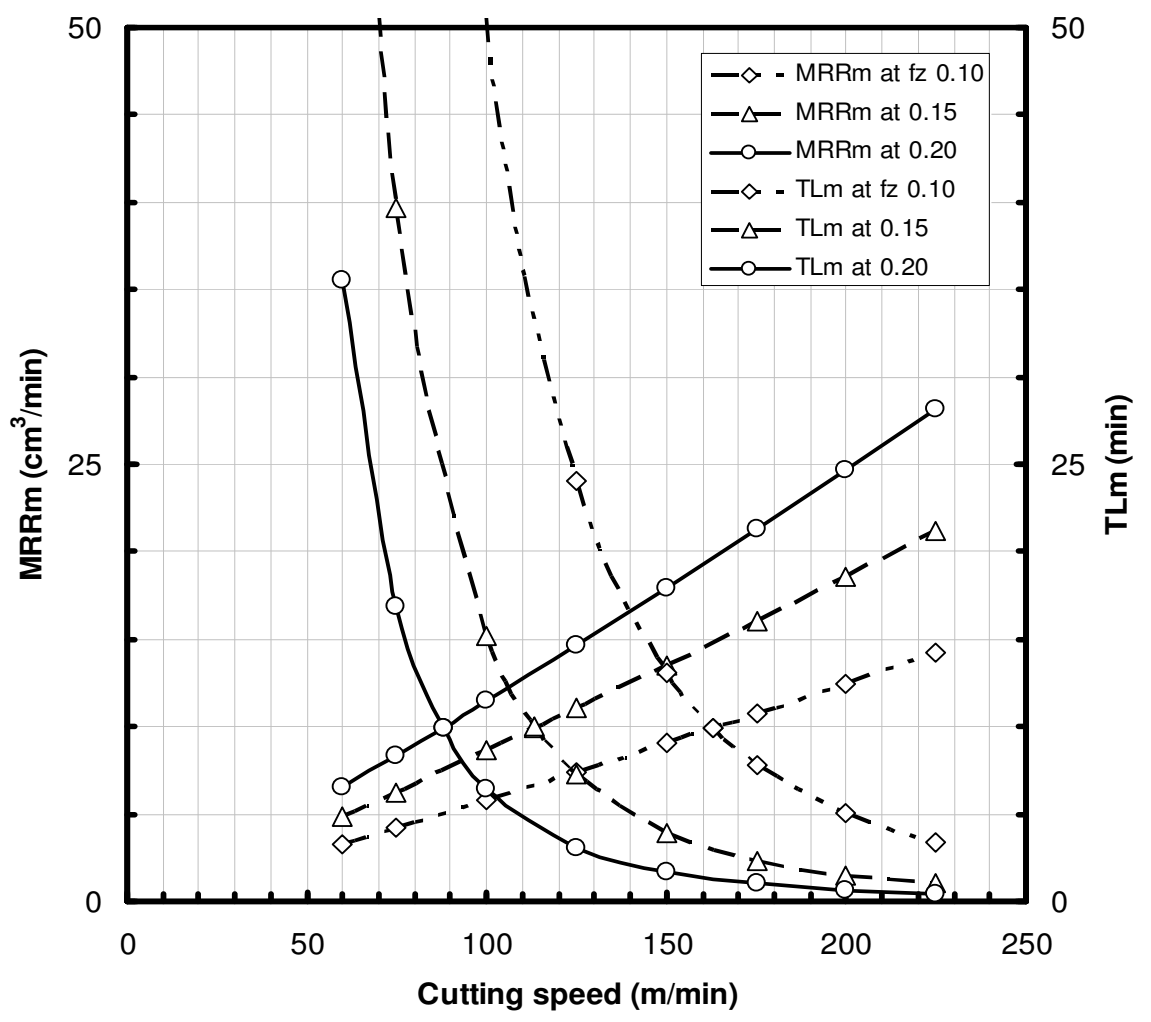

Fig. 7. Cutting speed (m/min) vs. Metal Removal Rate Model (MRRm) $\left(\mathrm{cm}^{3} / \mathrm{min}\right)$ and Tool Life Model (TLm) (m/min).

\section{CONCLUSIONS}

At the end of this paper, it can be concluded that the alloyed carbide tool used in this study show a good performance when used in end milling of the aeronautical material Ti-6242S under green / dry machining environment. Tool life is recorded ranging from 5 to 15 minutes at cutting speeds of $100-115 \mathrm{~m} / \mathrm{min}$, and these cutting speeds is much higher than the common cutting speed of titanium machining using carbide $(60 \mathrm{~m} / \mathrm{min})$. Although not reported detail in this paper, it can be noted that at the range of speeds, surface topography is found good in term of surface roughness.

In term of the extended Taylor tool life (T) model and the volume of material removed (Q) model, the performance of the alloyed carbide tool can be given by:

$T V_{c}^{3.3} f_{z}^{2.97} a_{a}{ }^{2.8}=1.767 \times 10^{6}$

$Q V_{c}^{2.2} f_{z}^{1.98} a_{a}{ }^{1.96}=3.318 \times 10^{3}$

From the models, three optimum cutting conditions are resulted; they are $(88 \mathrm{~m} / \mathrm{min}, 0.2 \mathrm{~mm} /$ tooth $),(113.5$ $\mathrm{m} / \mathrm{min}, 0.15 \mathrm{~mm} /$ tooth $)$ and $(163 \mathrm{~m} / \mathrm{min}, 0.1 \mathrm{~mm} /$ tooth $)$. Those three pairs of cutting conditions represent the best compromise condition among cutting speed, tool life and material removal rate. In the meaning of having further understanding, we note that further study will be carried out to verify whether the optimum cutting condition can also be achieved in lower cutting speed to obtain higher material removal rate and longer tool life by increasing the load of cutting (feed). It is important because higher material removal rate in lower cutting cannot simply be achieved by heavier feeding.

At the optimum cutting conditions, it can be interpreted that the tool failure mode, tool wear mechanism and the behaviour of tool performance are changing from mechanical load phenomenon to thermal load phenomenon. We note that it is natural since the higher the cutting speed the higher is the cutting temperature (thermal load).

By utilizing the FEM simulation, the chip morphology, contact length at the tool-chip interface and the tribological aspects (temperature, pressure) in machining at the optimum cutting conditions can be evaluated. The results of simulation support the interpretation of experimental results. 


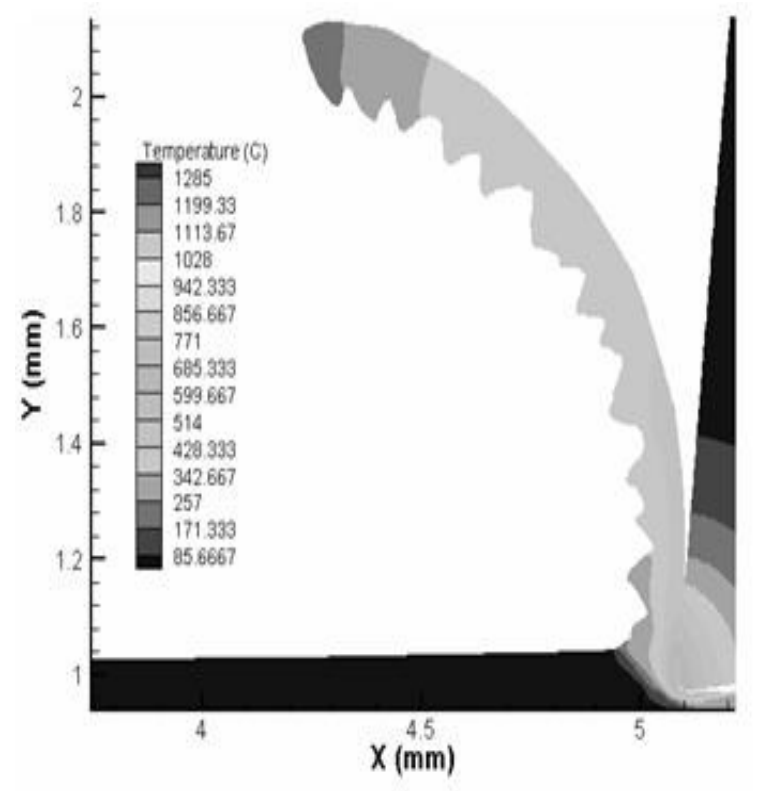

(a)

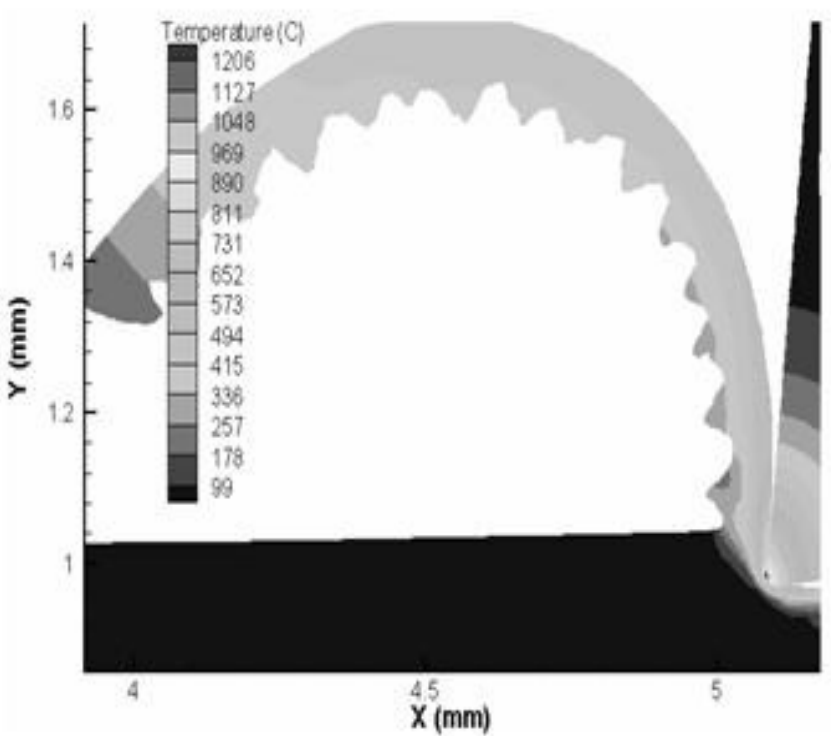

(b)

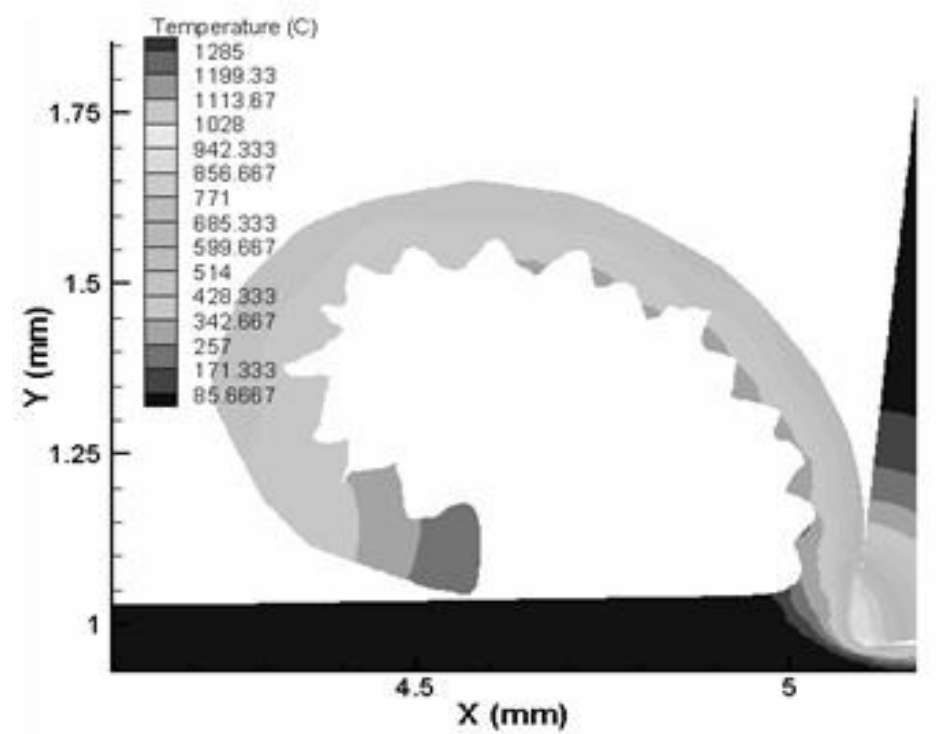

(c)

Fig. 8. Chip morphology and temperature distribution of machining simulations. (a) $63 \mathrm{~m} / \mathrm{min}, 0.1 \mathrm{~mm} /$ tooth, (b) $113.5 \mathrm{~m} / \mathrm{min}, 0.15 \mathrm{~mm} /$ tooth, (c) $163 \mathrm{~m} / \mathrm{min}, 0.2 \mathrm{~mm} / \mathrm{tooth}$.

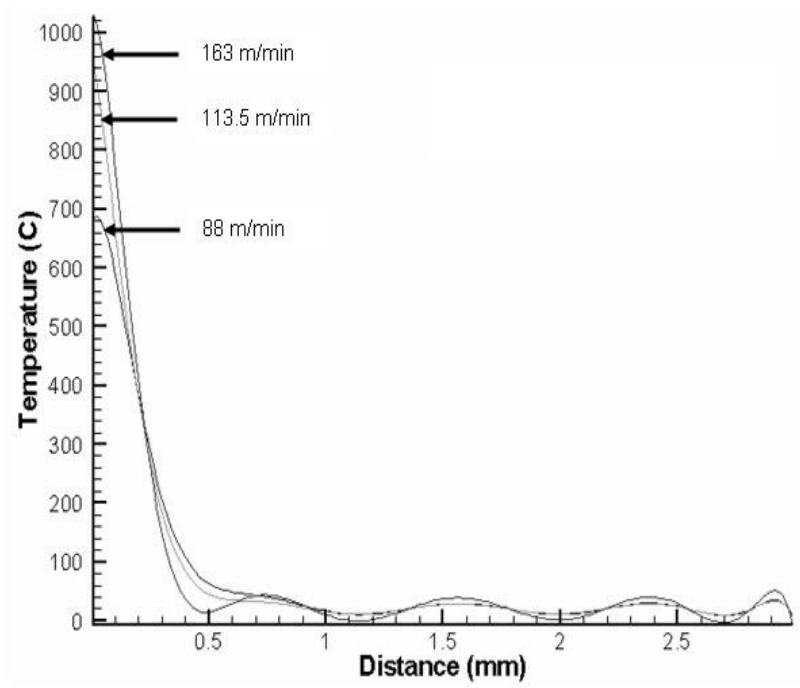

Fig. 9. Cutting temperature of optimum cutting speeds in comparison.

\section{ACKNOWLEDGMENT}

The author would like to thanks the LAMEFIP ENSAM CER Bordeaux, France for the visiting professor program and the continuation of joint research.

\section{REFERENCES}

[1] Sreejith, P.S., Ngoi, B.K.A., "Dry machining: machining of the future," J. Mater. Proc. Technol. 101: 287. 2000.

[2] Boyer, R.R., 1996, "An overview on the use of titanium in the aerospace industry," Mater. Sci. and Eng. A213: 103 114. 1996.

[3] ISO 8688-2, "Tool life testing in milling" - Part 2. End milling. 1989.

[4] Montgomery, D.C., Design and analysis of experiments. John Wiley \& Sons. 1991.

[5] Freeman, R.M., "The machining of titanium and some of its alloys," Ph.D Thesis, University of Birmingham, UK. 1974.

[6] Hartung, P.D, Kramer, B.M., "Tool wear in machining titanium," Annals of the CIRP 31/1: 75. 1982 
[7] Dearnley, P.A, Grearson, A.N., "Evaluation of principal wear mechanism of cemented carbide and ceramics used for machining titanium alloys IMI318," Mater. Sci. Technol. 2: 47. 1986. 